\title{
Effects of synthesis conditions on chemical structures and physical properties of copolyesters from lactic acid, ethylene glycol and dimethyl terephthalate
}

\author{
M. Opaprakasit ${ }^{*}$, A. Petchsuk ${ }^{2}$, P. Opaprakasit ${ }^{3}$, S. Chongprakobkit ${ }^{4}$ \\ ${ }^{1}$ Department of Materials Science, Faculty of Science, Chulalongkorn University, Bangkok, 10330 Thailand \\ ${ }^{2}$ National Metal and Materials Technology Center, Thailand Science Park, Pathumthani 12120 Thailand \\ ${ }^{3}$ Department of Common and Graduate Studies, Sirindhorn International Institute of Technology (SIIT), Thammasat \\ University, Pathumthani 12121 Thailand \\ ${ }^{4}$ Nanoscience and Technology Program, Chulalongkorn University, Bangkok, 10330 Thailand
}

Received 2 March 2009; accepted in revised form 15 May 2009

\begin{abstract}
Lactic acid/ethylene terephthalate copolyesters were synthesized by the standard melt polycondensation of lactic acid (L), ethylene glycol (EG) and dimethyl-terephthalate (DMT). Effects of reaction temperatures and types of catalysts on the structures and properties of the copolymers were examined. In addition, feasibility of promoting the copolymerization process by a novel synthesis step of using thermo-stabilizers was investigated. The results show that a reaction temperature of higher than $180^{\circ} \mathrm{C}$ is necessary to produce copolymers with appreciable molecular weight. However, degradation was observed when the reaction temperature is higher than $220^{\circ} \mathrm{C}$. Triphenyl phosphate (TPP) shows promising results as a potential thermo-stabilizer to minimize this problem. It was found that $\mathrm{Sb}_{2} \mathrm{O}_{3}$ and $\mathrm{Tin}$ (II) octoate are most effective among 4 types of catalysts employed in this study. ${ }^{1} \mathrm{H}-\mathrm{NMR}$ results indicate that copolymers have a random microstructure composed mainly of single L units alternately linked with ET blocks at various sequential lengths. The longer ET sequence in the chain structure leads to the increase in melting temperature of the copolymer. TGA results show that the resulting copolymers possessed greater thermal stability than commercially-available aliphatic PLA, as a result of the inclusion of $\mathrm{T}$ (terephthalate) units in the chain structure.
\end{abstract}

Keywords: biodegradable polymers, poly(lactic acid), poly(ethylene terephthalate), aliphatic aromatic copolyester, polymer synthesis

\section{Introduction}

Global warming is regarded as the most important and serious environmental issue. The major cause of this problematic phenomenon is the rapid increase in the release of greenhouse gases to the atmosphere as a result of high petroleum consumption. From the polymer science point of view, this issue is related to the rapid increase in consumption of petroleum-based commodity plastics, which are mostly non-degradable. In the past, the typical method for disposing of these plastic wastes was landfills. However, reduction in the number of landfill sites presently causes an accumulation of tremendous amounts of plastic waste. Alternatively, polymer recycling, i.e., mechanical recycling and energy recycling have been employed. This method, in turn, causes deterioration in physical properties of the recycled products, and emits some toxic products and greenhouse gases from incineration. Therefore, (bio)degradable plastics 
have been taken into consideration to reduce the impact of plastic waste on the environment. Moreover, polymers synthesized from renewable resources have been considered more sustainable than the conventional ones to overcome a shortage and the high cost of petroleum sources.

During the past two decades, more than 16 million kilograms of (bio)degradable polymers have been commercialized per year, of which $80 \%$ were used in loose-fill packaging applications. Other applications included compost bags, agricultural mulch films, paper coating, medical applications, and hygienic products [1]. Commercially available (bio)degradable polymers are classified into three groups: polyolefin/additives, starch blends, and polyesters [2]. Among these, aliphatic polyesters have received the most attention due to their (bio)degradability and versatile physical, mechanical, and biological properties. Susceptibility of carboxyl groups in the main chain of aliphatic polyesters to hydrolysis is well known. The common example of these materials is poly(lactic acid) or polylactide (PLA).

PLA is the most popular material among aliphatic polyesters due to its environmentally friendly properties. Its monomer, lactic acid, is derived from fermentation of agricultural products such as starch or sugar. In addition, high molecular weight PLA is proven as a biocompatible material with mechanical properties comparable to other commodity plastics, e.g., PE, PS and PP. In contrast, aromatic polyesters such as poly(ethylene terephthalate) (PET) have been reported as non-degradable materials [3]. Their physical properties, however, are much better than those of their aliphatic counterparts. This fact has initiated an idea of combining the degradability of aliphatic polyesters and the superior mechanical properties of aromatic polyesters to achieve novel copolyesters. This concept has been employed in improving degradability of PET [4-10], poly(propylene terephthalate) (PPT) [10-12], Poly(butylene terephthalate) (PBT) [10, 13-14], and poly(1,2-propanediyl phthalate) (PPP) [15] by incorporating diols and/or diacids into their main chains. The results revealed that the degradation rate of the resulting copolymers was influenced by the content of aromatic constituents [10, 13], chemical structures, i.e., random, block or alternating structure, solid state structure (semi- crystalline or amorphous), and chain mobility [14]. For example, copolyester derived from butanediol, adipic acid, and terephthalic acid under a trade name Ecoflex ${ }^{\circledR}$ is claimed to have good mechanical properties and a fully biodegradable property with minimum toxicological effect on the environment [16].

Many reports in the literature have focused on aliphatic-aromatic copolyesters derived from petroleum-based monomers. Only a small number of studies on copolyesters based on renewable lactic acid have been reported [17-20]. Olewnik and coworkers reported that a degradable poly(lactic acidco-ethylene terephthalate) can be synthesized from lactic acid and PET-glycolized products [19-20]. However, to our knowledge, limited information on the effect of reaction conditions on the properties and microstructures of the synthesized copolymers is available in the literature.

In this communication, we report results on the synthesis and characterization of poly(lactic acidco-ethylene terephthalate) from lactic acid and dimethyl terephthalate monomers, and ethylene glycol. Although the standard method of polycondensation is employed in the synthesis, this work attempts to enhance the synthesis reaction by focusing on effects of reaction conditions on the chemical structure and properties of the copolyesters; especially reaction temperature and time, type of catalysts, and the stoichiometry of the comonomer feed. Additionally, a novel synthesis step of employing thermo-stabilizers in the reaction to enhance the extent of reaction at high temperature will be discussed.

\section{Experimental}

\subsection{Materials}

Lactic acid (88\% wt aqueous solution) and ethylene glycol were purchased from Carlo Erba. Dimethyl terephthalate was supplied by Acros. p-Toluene sulfonic acid (PTSA), Titanium(IV) tetra(n-butoxide) $\mathrm{Ti}(\mathrm{OBu})_{4}$, Antimony trioxide $\left(\mathrm{Sb}_{2} \mathrm{O}_{3}\right)$ and Triphenyl phosphate (TPP) were obtained from Sigma-Aldrich. Tin(II) octoate and tin chloride were provided by Wako Chemicals and Fluka, respectively. Irganox-1076 and Zn-stearate were supplied by Ciba Specialty Chemicals. All chemicals were used without purification. 


\subsection{Synthesis of lactic acid/ethylene terephthlate copolymers}

Copolymers were synthesized via polycondensation reaction by using lactic acid (LA) and monomers of PET, i.e., dimethyl terephthlate (DMT) and ethylene glycol (EG). Effects of reaction temperature and time were first investigated. Essentially, DMT, LA and $0.5 \%$ wt of Tin(II) octoate catalyst were added into a round bottom flask equipped with condenser, nitrogen gas inlet, thermometer and vacuum line. The mixture was kept isothermally at $160^{\circ} \mathrm{C}$ for a certain time after DMT was completely melted. EG was then added and the temperature was raised stepwise and kept isothermally between 180 and $220^{\circ} \mathrm{C}$. Isothermal time at each temperature increment was varied in reaction batches no.1-4, as indicated in Table 1. A 1:1:1 molar ratio of LA, DMT, and EG was used unless other composition is indicated.

Effects of different types of thermo-stabilizers (i.e., Irganox-1076, Zn-stearate, and TPP), and catalysts (i.e., Tin chloride with PTSA, $\operatorname{Ti}(\mathrm{OBu})_{4}$, and $\mathrm{Sb}_{2} \mathrm{O}_{3}$ ) on the extent of polymerization reaction were also investigated by keeping a constant content of thermo-stabilizers and catalysts at $0.1 \%$ and $0.5 \%$ by weight of comonomers, respectively. The optimum reaction temperature and time obtained from batch no. 4 was employed in these successive reactions (batches no.5-11).

\subsection{Characterizations of lactic acid/ethylene terephthlate copolymers}

\subsubsection{Gel Permeation Chromatography (GPC)}

Molecular weight of the as-synthesized copolyesters was examined by a Waters $150 \mathrm{CV}$, using THF as a solvent with a flow rate of $1 \mathrm{ml} / \mathrm{min}$. Mono-dispersed polystyrenes were used as standard materials for constructing a calibration curve.

\subsection{2. ${ }^{1} \mathrm{H}-\mathrm{NMR}$ spectroscopy}

Chemical and sequential structures of copolyesters were determined by $300 \mathrm{MHz}{ }^{1} \mathrm{H}-\mathrm{NMR}$ analysis on a Bruker DPX300 spectrometer using chloroform-d as a solvent and TMS reference, with a repetition delay of 2 seconds. For copolyesters insoluble in chloroform, chloroform-d/trifluoroacetic acid mixed solvent was employed.

Assuming the exclusion of side reactions, the possible sequential structures of copolyesters obtained in this work are illustrated in Figure 1. The chemical shift and assignments of proton signals observed in NMR spectra are shown in Figure 2. The average length of $\mathrm{ET}$ and $\mathrm{L}$ sequences, $\mathrm{X}_{(\mathrm{ET})}$ and $\mathrm{Y}_{(\mathrm{L})}$, in the copolymers can be calculated according to Grzebieniak et. al. $[17,18]$ from the integrals of the signals LT ( 5.33 ppm), LL ( $5.16 \mathrm{ppm})$, TET ( 4.66 ppm), and TEL ( 4.52 ppm) (Equations (1) and (2)):

$$
\begin{aligned}
& \mathrm{Y}_{(\mathrm{L})}=(\mathrm{LL} / \mathrm{LT})+1 \\
& \mathrm{X}_{(\mathrm{ET})}=(\mathrm{TET} / \mathrm{TEL})+1
\end{aligned}
$$

Table 1. Effects of reaction temperature and time on reaction yield [\%], molecular weight, chemical structure, and transi-

\begin{tabular}{|c|c|c|c|c|c|c|c|c|c|c|c|c|c|c|}
\hline \multirow{2}{*}{$\begin{array}{c}\text { Batch } \\
\text { No. }\end{array}$} & \multirow{2}{*}{$\begin{array}{l}\text { Yield } \\
{[\%]}\end{array}$} & \multicolumn{3}{|c|}{$\begin{array}{c}\text { Reaction time }[\mathrm{hr}] \\
\text { at }\end{array}$} & \multicolumn{2}{|c|}{$\begin{array}{c}\text { Molecular } \\
\text { weight' }^{\mathrm{a}}\left(\mathbf{1 0}^{-3}\right)\end{array}$} & \multicolumn{2}{|c|}{$\begin{array}{l}\text { Sequential } \\
\text { length }^{b}\end{array}$} & \multicolumn{2}{|c|}{$\begin{array}{c}\text { Number-average } \\
\text { sequential } \\
\text { length }^{b}\end{array}$} & \multirow{2}{*}{$\begin{array}{c}\mathrm{T} / \mathrm{L} \\
\text { ratio }^{\mathbf{b}}\end{array}$} & \multirow{2}{*}{$\mathbf{B}^{\mathbf{b}}$} & \multicolumn{2}{|c|}{$\begin{array}{c}\text { Transition } \\
\text { temperatures }\left[{ }^{\circ} \mathrm{C}\right]\end{array}$} \\
\hline & & $180^{\circ} \mathrm{C}$ & $200^{\circ} \mathrm{C}$ & $220^{\circ} \mathrm{C}$ & $M_{n}$ & $\mathbf{M}_{\mathbf{w}}$ & $\mathbf{Y}_{(\mathbf{L})}$ & $\mathbf{X}_{(\mathbf{E T})}$ & $\mathbf{L}_{\mathbf{n}, \mathbf{L}}$ & $\mathbf{L}_{\mathbf{n}, \mathbf{E T}}$ & & & $\mathbf{T}_{\mathrm{g}}$ & $\begin{array}{c}\mathbf{T}_{\mathrm{m}} \\
\left(\Delta \mathbf{H}_{\mathrm{m}}[\mathbf{J} / \mathbf{g}]\right)\end{array}$ \\
\hline \multirow{3}{*}{1} & \multirow{3}{*}{75} & 1 & - & - & 0.3 & 0.6 & N/A & N/A & N/A & N/A & N/A & N/A & N/A & N/A \\
\hline & & 5 & - & - & 0.7 & 0.9 & N/A & N/A & N/A & N/A & N/A & N/A & N/A & N/A \\
\hline & & 7 & - & - & 0.8 & 1.1 & 1.7 & 1.9 & 1.4 & 4.1 & 1.5 & 0.96 & - & 119,134 \\
\hline 2 & 66 & 1 & 4 & - & 1.6 & 2.1 & 1.3 & 2.4 & 1.4 & 4.4 & 1.6 & 0.95 & 9.6 & $149.4(5)$ \\
\hline \multirow{2}{*}{3} & N/A & 1 & 2 & 2 & 1.7 & 2.3 & N/A & N/A & N/A & N/A & N/A & N/A & N/A & N/A \\
\hline & 70 & 1 & 2 & 4 & 3.3 & 5.4 & 1.2 & 2.9 & 1.9 & 5.1 & 1.3 & 0.71 & 52.2 & $173.2(10)$ \\
\hline $4 c$ & 58 & 1 & 2 & 4 & 6.7 & 12.4 & 1.2 & 2.9 & 1.3 & 5.2 & 1.9 & 0.94 & 48.1 & $176.6(2)$ \\
\hline
\end{tabular}
tion temperatures of the as-synthesized copolyesters

aResults from GPC experiments

bCalculated from ${ }^{1} \mathrm{H}-\mathrm{NMR}$ spectra

${ }^{\mathrm{c}}$ After holding the temperature at $220^{\circ} \mathrm{C}$ for 1 hour, an equivalent molar of EG to DMT was added to ensure an adequate amount of EG remained in polymerization reaction 


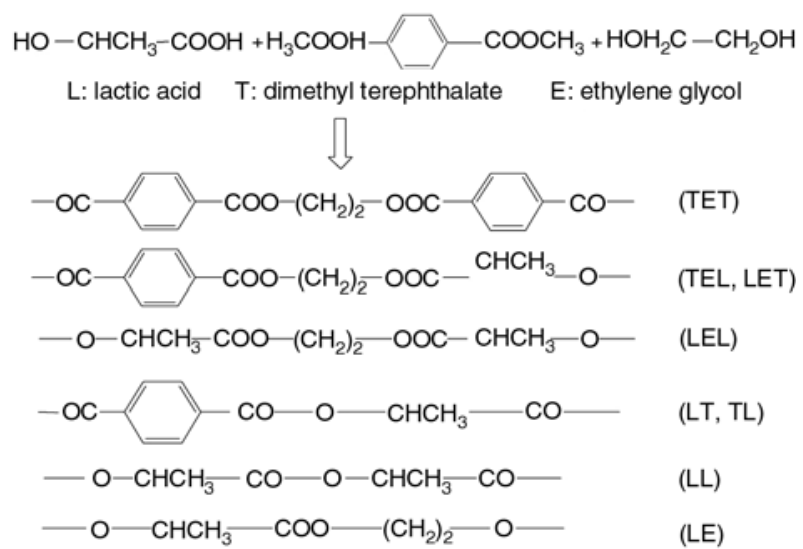

Figure 1. Possible E-centered triads and diads of the resulting copolyesters

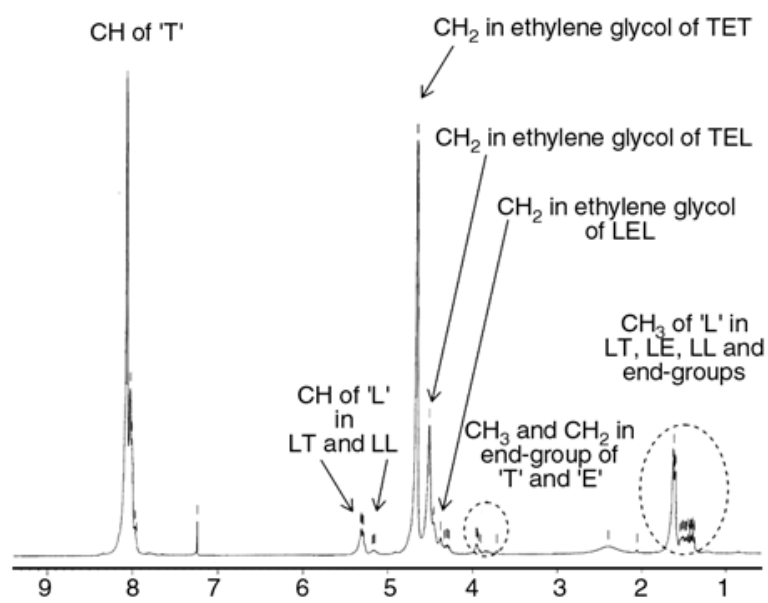

Figure 2. ${ }^{1} \mathrm{H}-\mathrm{NMR}$ spectrum of as-received copolyester obtained from batch no. 4 and its signal assignments

In Olewnik et al. [19], results on chemical and sequential structure of copolyesters synthesized from lactic acid and bis(2-hydroxyethyl terephthalate) (BHET) by employing NMR spectra were reported. The authors extensively discussed proton assignments of the resulting poly(lactic acid-coterephthalate). Furthermore, number-average molar mass $\left(M_{n}\right)$, degree of randomness (B), T/L ratio, and number-average number of ET and L units in the copolyester chains $\left(\mathrm{L}_{\mathrm{n}, \mathrm{ET}}\right.$ and $\left.\mathrm{L}_{\mathrm{n}, \mathrm{L}}\right)$ were also calculated $[19,21]$. Although, copolyesters synthesized in our work are derived from different monomers used in Olewnik et al. [19], the NMR spectra of our copolymers show signals associated with all possible E-centered triads and diads in $3.5-5.5 \mathrm{ppm}$ region. This indicates that the copolymers are consisting of all similar possible connections to those synthesized from lactic acid and
BHET [19]. Therefore, the calculation method was adopted in this work. However, the relative integration of these signals varies with the synthesis conditions in our work. This reflects that the microstructure of the copolyesters can be controlled by using lactic acid, ethylene glycol and DMT as monomers, and varying synthesis conditions.

\subsubsection{Differential Scanning Calorimetry (DSC)}

DSC thermograms were recorded by employing a Mettler Toledo DSC822e. First and second heating thermograms were collected from samples of $10-15 \mathrm{mg}$. The sample was heated from -20 to $200^{\circ} \mathrm{C}$ at a rate of $10^{\circ} \mathrm{C} / \mathrm{min}$. After the $1^{\text {st }}$ heating scan, the sample was cooled to $-10^{\circ} \mathrm{C}$ at a rate of $10^{\circ} \mathrm{C} / \mathrm{min}$. Glass transition temperature $\left(T_{g}\right)$, melting temperature $\left(T_{m}\right)$, and heat of melting $\left(\Delta H_{m}\right)$ were derived from the $2^{\text {nd }}$ heating thermograms.

\subsubsection{Thermogravimetric Analysis (TGA)}

Thermo-stability of the copolyesters was characterized by a Mettler Toledo TGA/SDTA 851 under oxygen atmosphere. Samples of $10-15 \mathrm{mg}$ were heated from 50 to $1000^{\circ} \mathrm{C}$ at a rate of $20^{\circ} \mathrm{C} / \mathrm{min}$.

\subsubsection{Reduced viscosity}

Reduced viscosity of the copolyesters was determined at $25^{\circ} \mathrm{C}$ using a $0.2 \mathrm{~g} / \mathrm{dl}$ solution in a $7 \%$ trichloroacetic acid/chloroform mixed solvent. The solutions were freshly prepared and measured to prevent the possibility of copolymer degradation.

\subsubsection{Solubility test}

Solubility of copolymers was determined by dissolving $0.5 \mathrm{~g}$ of samples in $10 \mathrm{ml}$ of chloroform or a trichloroacetic/chloroform mixed solvent at room temperature. The solubility is indicated by number of ' + '. Essentially, the samples were first dissolved in chloroform. If a complete dissolution is achieved within 10 minutes at ambient temperature, solubility is rated as ' +++ '. For samples taken longer time to completely dissolve in chloroform, the solubility was measured in a trichloroacetic acid/chloroform mixed solvent. The rating of ' ++ ' and ' + ' indicates 
that the samples are fully dissolved in $2 \%(\mathrm{w} / \mathrm{w})$ and $5 \%$ of trichloroacetic acid/chloroform mixed solvent within 10 minutes, respectively.

\section{Results and discussion}

\subsection{Effects of reaction temperature and time}

Effects of reaction temperature and time on the extent of polymerization, chemical structure, and transition temperatures of the copolyesters, using a typical Tin(II) octoate catalyst, were conducted in batches no.1-4. The results are shown in Table 1, where average molecular weights derived from GPC experiments and chemical structure parameters; including $\mathrm{T} / \mathrm{L}$ ratio, degree of randomness (B) and sequential length of ET and L examined from ${ }^{1} \mathrm{H}-\mathrm{NMR}$ using the methods of Grzebieniak et al. [17, 18], Olewnik et al. [19], and Tessier and Fradet [21] are compared. The results clearly indicate that number and weight average molecular weights of the copolyesters are strongly dependent on reaction temperature. Results from batches no.1-3 show that higher molecular weight copolymers were obtained at higher polymerization temperatures, when similar reaction time was employed. The drastic increase in molecular weight of copolyesters observed in batches no.2-4 compared to that of batch no. 1 indicates that a reaction temperature higher than $180^{\circ} \mathrm{C}$ is required in order to successfully synthesize high molecular weight material at a practical reaction time.

An attempt to use a reaction temperature higher than $220^{\circ} \mathrm{C}$ was conducted, but a serious degradation of the copolyesters was observed, where darker color product was produced. Therefore, the reaction condition used in batch no.3, i.e., reaction temperature of 180 to 200 and $220^{\circ} \mathrm{C}$ with total reaction time of 7 hours, was employed as optimum conditions for successive batches. Copolymer with $M_{w}$ of $5.4 \cdot 10^{3} \mathrm{~g} / \mathrm{mole}$ and reduced viscosity of $0.12 \mathrm{dl} / \mathrm{g}$ was obtained in this batch. It was speculated that some EG might be removed along with the removal of condensed water and methanol molecules during the reaction when the reaction temperature higher than $200^{\circ} \mathrm{C}$ was employed. This leads to a lowering of EG content in the mixture and, hence, inhibits the polymerization in reaching a higher extent. To prove this hypothesis, the reaction in batch no.4 was carried out by employing a similar reaction temperature and time to that of batch no.3, but an additional amount of EG (1 equivalent molar to DMT) was introduced into the reaction flask after a certain time at $220^{\circ} \mathrm{C}$. This results in an increase in $M_{w}$ (approximately twofold compared to that of batch no.3). Since the copolymers from these two batches were synthesized using similar reaction conditions, this clearly provides good evidence that a non-stoichiometric effect is the origin of the lower molecular weight materials obtained in batch no.3. Furthermore, the addition of the excess EG employed in batch no. 4 also affects the T/L ratio of the resulting copolyesters, where a much higher ratio was obtained. The reason for this is probably because EG acts as diol that is required for incorporating diacids (DMT) into the copolymer chain. Therefore, the $\mathrm{T}$ content of the chain is promoted when EG composition in the reaction is maintained.

NMR spectra of copolyesters obtained from batches no.1-4 are shown in Figures 3a-d, respectively. The presence of proton signals of LT $(\sim 5.33 \mathrm{ppm})$ and TEL $(\sim 4.52 \mathrm{ppm})$ sequences provides a good evidence for linkages of lactic acid and ethylene terephthalate groups, indicating a successful production of lactic acid-co-ethylene terephthalate structure. Additionally, the spectra show significant difference in intensities of signals

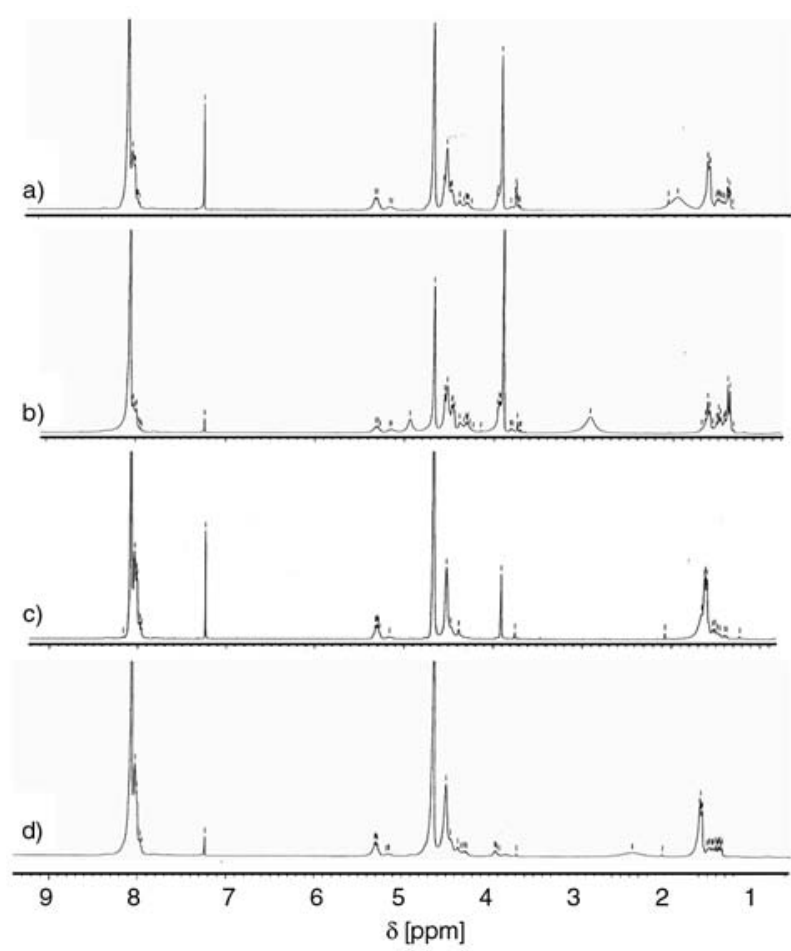

Figure 3. ${ }^{1} \mathrm{H}-\mathrm{NMR}$ spectra of as-received copolyesters obtained from batches no.1 (a), no.2 (b), no.3 (c), and no.4 (d) 
located between 3.7 and $4.0 \mathrm{ppm}$, especially the peak at $\sim 3.9 \mathrm{ppm}$. These signals originate from the $\mathrm{CH}_{2}$ proton in $\mathrm{E}$ end-groups and $\mathrm{CH}_{3}$ proton in DMT and T end-groups ( $3.93 \mathrm{ppm})$. The intensities of these peaks decrease from spectrum $3 \mathrm{a}$ to $3 \mathrm{~d}$, indicating a decrease in the number of chain-ends. This agrees with results obtained from GPC experiments that the average molecular weight of the copolymers increase as a result of increasing reaction temperature and time and the addition of excess amounts of ethylene glycol. It should be noted that a drop in intensity of the signal at $3.93 \mathrm{ppm}$ is also possibly related to the decrease of residue DMT in the mixture, which also indicates a higher extent of polymerization.

The chemical structures of copolymers synthesized as a function of reaction conditions are unveiled by the degree of randomness (B) and the number-average sequential length of ET and $L\left(L_{n, E T}\right.$ and $\left.L_{n, L}\right)$, as shown in Table 1. The B values of copolymers obtained from batches no.1, 2 and 4 are approaching the value of 1 , indicating a production of random copolymers regardless of the polymerization conditions. The corresponding values of $\mathrm{X}_{(\mathrm{ET})}$, $\mathrm{L}_{\mathrm{n}, \mathrm{ET}}, \mathrm{Y}_{(\mathrm{L})}$ and $\mathrm{L}_{\mathrm{n}, \mathrm{L}}$ imply that the chain structure of these copolyesters consists of a longer ET sequence, compared to LL sequence. Also, the values indicate that the sequential length of ET in the copolymers is much more sensitive to the synthesis conditions than that of its LL counterpart. In addition, the results suggest that a longer block of ET can be obtained by employing more severe reaction conditions.

The $\mathrm{Y}_{(\mathrm{L})}$ and $\mathrm{L}_{\mathrm{n}, \mathrm{L}}$ values, which indicate the probability of finding $\mathrm{L}$ next to another L unit, of copolyesters obtained from batches no.1-4 (as also shown in Table 1) are close to the minimum value of 1 , indicating a low probability of finding L to L linkage. This implies that almost all L units are separately linked to ET units or ET blocks (various lengths) in the copolymer chains. It should be noted that the addition of excess EG, which results in an increase in average molecular weight of the copolymer, has no significant effect on the sequential length of ET, as evidenced from the results of batches no. 3 and 4 .

Results on glass transition temperature $\left(T_{g}\right)$ and melting temperature $\left(T_{m}\right)$ of the copolymers from batches no.1-4 are also presented in Table 1. Single $T_{g}$, whose position is predominantly influenced by the molecular weight of copolyesters, is observed in all samples, i.e., higher $T_{g}$ is observed in samples with a lower number of end-groups (higher $M_{n}$ ). Melting peaks located at unusually low temperature and low values of $\Delta H_{m}$ were observed in samples from batches no. 1 and 2 . This is probably due to the melting of domain consisting of short-chain oligomers that possess chemical structures resembling BHET $\left(T_{m} \sim 106-109^{\circ} \mathrm{C}\right)$, and DMT residue $\left(T_{m} \sim 145^{\circ} \mathrm{C}\right)$. Although $T_{m}$ of samples from batches no. 3 and 4 is much higher, it is not comparable to that of neat PET $\left(\sim 255^{\circ} \mathrm{C}\right)$. This is probably because crystallizable portions of the copolymer chain are largely due to ET sequence. An inclusion of L units therefore interrupts the chain's ET sequence, which in turn leads to the lowering of $T_{m}$ of the copolyesters.

\subsection{Effect of thermo-stabilizers}

As mentioned earlier, a higher extent of polymerization can be achieved by increasing the synthesis temperature. However, degradation also competes strongly at higher temperature, noticeable by the yellowish color of the samples. It is speculated that a thermo-stabilizer is able to minimize degradation at the high reaction temperature. Therefore, this hypothesis is investigated by employing various types of thermo-stabilizers, i.e., Irganox-1076, Znstearate, and Triphenyl phosphate (TPP), as the first two compounds are common antioxidants in polymer processing, while TPP is usually employed as thermal stabilizer in the synthesis of commercial PET. A typical Tin(II) octoate was also used as a catalyst. Efficiency of these stabilizers in enhancing the synthesis reaction is examined by comparing the results with those obtained from copolymer of batch no.4, where no stabilizer is added.

Table 2 summarizes properties of the copolymers synthesized from reactions conducted by similar conditions without and with the use of various thermo-stabilizers. We first discuss the effects of thermo-stabilizers on the copolymers molecular weight. As copolymers obtained from these batches of reactions are hardly soluble in any common solvents, GPC cannot be employed as a primary technique in measuring the molecular weight. Alternately, relative molecular weights are examined by comparing the copolymers reduced viscosity in trichloroacetic acid/chloroform mixed solvent. It 
Table 2. Effects of thermo-stabilizers on reaction yield [\%], chemical structure and physical properties of the copolymers synthesized using tin(II) octoate as a catalyst

\begin{tabular}{|c|c|c|c|c|c|c|c|c|c|c|c|c|c|}
\hline \multirow{2}{*}{$\begin{array}{l}\text { Batch } \\
\text { No. }\end{array}$} & \multirow{2}{*}{$\begin{array}{l}\text { Thermo- } \\
\text { stabilizer }\end{array}$} & \multirow{2}{*}{$\begin{array}{l}\text { Yield } \\
{[\%]}\end{array}$} & \multirow{2}{*}{$\begin{array}{c}\text { Reduced } \\
\text { viscosity } \\
{[\mathrm{dl} / \mathrm{g}]}\end{array}$} & \multirow{2}{*}{$\begin{array}{l}\text { Solu- } \\
\text { bility }\end{array}$} & \multirow{2}{*}{$\begin{array}{c}\mathbf{M}_{\mathbf{n}} \\
\left(\mathbf{1 0}^{-3}\right)\end{array}$} & \multicolumn{2}{|c|}{$\begin{array}{l}\text { Sequential } \\
\text { length }\end{array}$} & \multicolumn{2}{|c|}{$\begin{array}{l}\text { Number-average } \\
\text { sequential length }\end{array}$} & \multirow[t]{2}{*}{$\begin{array}{l}\mathrm{T} / \mathrm{L} \\
\text { ratio }\end{array}$} & \multirow[t]{2}{*}{ B } & \multicolumn{2}{|c|}{$\begin{array}{c}\text { Transition } \\
\text { temperatures }\left[{ }^{\circ} \mathrm{C}\right]\end{array}$} \\
\hline & & & & & & $\mathbf{Y}_{(\mathbf{L})}$ & $\mathbf{X}_{(\mathbf{E T})}$ & $\mathbf{L}_{\mathbf{n}, \mathbf{L}}$ & $\mathbf{L}_{\mathbf{n}, \mathbf{E T}}$ & & & $\mathbf{T}_{\mathbf{g}}$ & $\begin{array}{c}\mathbf{T}_{\mathrm{m}} \\
\left(\Delta \mathbf{H}_{\mathrm{m}}[\mathrm{J} / \mathrm{g}]\right)\end{array}$ \\
\hline 4 & - & 58 & 0.16 & +++ & 3.5 & 1.2 & 2.9 & 1.3 & 5.2 & 1.9 & 0.94 & 48.1 & $176.6(2)$ \\
\hline 5 & Irgano & 50 & 0.17 & ++ & 2.3 & 1.2 & 3.2 & 1.5 & 6.3 & 2.1 & 0.84 & 53.2 & $174.9(20)$ \\
\hline 6 & n-stearate & 50 & 0.13 & + & 1.2 & 1.4 & 2.6 & 1.7 & 5.1 & 1.5 & 0.78 & 44.2 & $169.0(18)$ \\
\hline 7 & TPP & 56 & 0.17 & + & 1.6 & 1.3 & 3.4 & 1.4 & 7.0 & 2.6 & 0.87 & 41.9 & $182.4(20)$ \\
\hline $8^{a}$ & TPP & 58 & 0.13 & + & 3.6 & 1.2 & 3.2 & 1.2 & 5.9 & 2.4 & 0.99 & 50.3 & 190.9 (24) \\
\hline
\end{tabular}

aThermo-stabilizer was added into the reaction prior to raising the temperature to $200^{\circ} \mathrm{C}$. In other batches, thermo-stabilizer was introduced after a completion of the reaction step at $200^{\circ} \mathrm{C}$.

should be noted that the employment of strong acid such as trichloroacetic acid or trifluoroacetic acid as a mixed solvent for ET-based (co)polymers may result in end-groups modification, as reported by Kenwright and coworkers [22] that these strong acids slowly reacted with hydroxyl end-groups by esterification. The authors, however, observed no polymers degradation when the strong acids were employed. Given this finding, our measurement of reduced viscosity was carefully conducted by using freshly-prepared solutions with minimum amount of the acids $(\sim 7 \%)$. The reduced viscosity, however, shows no correlation between the molecular weight and the thermo-stabilizers efficiency, as opposed to that observed in NMR results. This is probably because of the low sensitivity of the technique. Molecular weight calculated from NMR spectra shows that samples from batches no.5-7 had significantly lower $M_{n}$ than that of batch no.4, implying that the addition of these additives impedes the polymerization reaction. Besides inhibiting the reaction, the addition of these thermostabilizer also affect the copolymer microstructure. This is evidenced from the degree of randomness (B) values of lower than 1 of copolymer from batches no.5-7, indicating block structure and a much longer (average) sequential length of ET and L, compared to other batches (see Table 2).

Interestingly, the $M_{n}$ value of copolymer from batch no.8, where TPP was applied as thermo-stabilizer prior to raising the temperature to $200^{\circ} \mathrm{C}$, is higher than that of batch no.7, where the stabilizer was added after completion of a reaction step at $200^{\circ} \mathrm{C}$, and that of batch no.4, where no stabilizer was added. $T_{g}$ and $T_{m}$ values of copolymer obtained form batch no. 8 are also higher than those of no.4, indicating larger molecules. The appearance of the resulting copolymers (lighter color) also reflects the inhibition of the competing degradation during the polymerization. Given similar reaction conditions used in these reactions, the results indicate that TPP acts efficiently as a thermo-stabilizer for poly(lactic acid-co-ethylene terephthalate) when the reagent is added at an early stage of reaction at low temperature.

\subsection{Effect of catalysts}

To further improve the efficiency of the synthesis reaction, various types of catalysts were employed in the reaction batches no.9-11, i.e. Tin chloride with PTSA, $\mathrm{Ti}(\mathrm{OBu})_{4}$ and $\mathrm{Sb}_{2} \mathrm{O}_{3}$. These catalysts were selected because the first two are commonly used in polycondensation of PLA, and $\mathrm{Sb}_{2} \mathrm{O}_{3}$ is a common catalyst for the synthesis of commercial PET. The results are then compared with that of batch no.4, where the typical Tin(II) octoate was used. The properties of the resulting copolymers are summarized in Table 3. The results on $M_{n}$, chemical structure, and transition temperatures of all copolymers from batches no.4, 9-11 are strongly dependent on catalytic systems. The reduced viscosity results, however, are significantly comparable, which is not correlated with $M_{n}$ values calculated from NMR spectra, as a result of the low sensitivity of the technique. Nonetheless, it can be interpreted from the degree of randomness that random structure $(\mathrm{B} \sim 1)$ is obtained when copolymers are synthesized beyond a moderate value of $M_{n}(\sim 2000)$ regardless of the types of catalysts. It can be concluded that among the three types of novel catalysts employed in this study, 
Table 3. Effects of catalyst systems on reaction yield [\%], chemical structure and physical properties of the copolymers

\begin{tabular}{|c|c|c|c|c|c|c|c|c|c|c|c|c|c|}
\hline \multirow{2}{*}{$\begin{array}{c}\text { Batch } \\
\text { No. }\end{array}$} & \multirow{2}{*}{ Catalyst } & \multirow{2}{*}{$\begin{array}{c}\text { Yield } \\
{[\%]}\end{array}$} & \multirow{2}{*}{$\begin{array}{c}\text { Reduced } \\
\text { viscosity } \\
{[\mathrm{dl} / \mathrm{g}]}\end{array}$} & \multirow{2}{*}{$\begin{array}{l}\text { Solu- } \\
\text { bility }\end{array}$} & \multirow{2}{*}{$\begin{array}{c}\mathbf{M}_{\mathbf{n}} \\
\left(\mathbf{1 0}^{-3}\right)\end{array}$} & \multicolumn{2}{|c|}{$\begin{array}{l}\text { Sequential } \\
\text { length }\end{array}$} & \multicolumn{2}{|c|}{$\begin{array}{l}\text { Number-average } \\
\text { sequential length }\end{array}$} & \multirow[t]{2}{*}{$\begin{array}{l}\mathrm{T} / \mathrm{L} \\
\text { ratio }\end{array}$} & \multirow[t]{2}{*}{ B } & \multicolumn{2}{|c|}{$\begin{array}{c}\text { Transition } \\
\text { temperatures }\left[{ }^{\circ} \mathbf{C}\right]\end{array}$} \\
\hline & & & & & & $\mathbf{Y}_{(\mathbf{L})}$ & $\mathbf{X}_{(\mathrm{ET})}$ & $\mathbf{L}_{\mathbf{n}, \mathbf{L}}$ & $\mathbf{L}_{\mathbf{n}, \mathbf{E T}}$ & & & $\mathbf{T}_{\mathrm{g}}$ & $\begin{array}{c}\mathbf{T}_{\mathrm{m}} \\
\left(\Delta \mathbf{H}_{\mathrm{m}}[\mathrm{J} / \mathrm{g}]\right)\end{array}$ \\
\hline 4 & $\begin{array}{l}\text { Tin (II) } \\
\text { octoate }\end{array}$ & 58 & 0.16 & +++ & 3.5 & 1.2 & 2.9 & 1.3 & 5.2 & 1.9 & 0.94 & 48.1 & $176.6(2)$ \\
\hline 9 & $\begin{array}{l}\text { PTSA, } \\
\text { Tin chloride }\end{array}$ & 56 & 0.16 & +++ & 2.1 & 1.2 & 2.3 & 1.1 & 7.7 & 3.4 & 1.01 & 35.3 & - \\
\hline 10 & $\mathrm{Ti}(\mathrm{OBu})_{4}$ & 58 & 0.14 & + & 1.6 & 1.3 & 2.8 & 1.7 & 5.2 & 1.5 & 0.78 & 24.9 & $163.9(13)$ \\
\hline 11 & $\mathrm{Sb}_{2} \mathrm{O}_{3}$ & 60 & 0.13 & + & 4.5 & 1.2 & 3.2 & 1.2 & 5.8 & 2.6 & 1.03 & 52.4 & $185.1(17)$ \\
\hline
\end{tabular}

$\mathrm{Sb}_{2} \mathrm{O}_{3}$ provides higher efficiency in producing copolymers with higher $M_{n}$ and $T_{m}$, compared to the commonly-used Tin(II) octoate catalyst.

\subsection{Chemical structure, thermal properties, and solubility}

Grzebieniak reported that physicochemical properties of ethylene terephthalate/lactic acid copolyesters are dependent on the length of ET and L sequences [17]. The authors concluded that the length of ET and L sequence in the copolymers was dependent on the synthesis approach, in which the values increased in ascending order when synthesis reaction were changed from melt-polycondensation (approach I) to trans-esterification of PET and Llactide (approach II) and to trans-esterification of PET and PLA (approach III), respectively. As a consequence, copolymers from approach I and II can dissolve easier in organic solvents, such as chloroform. The authors also reported that samples synthesized from approach I showed lower $T_{m}$ and lower heat of melting $\left(\Delta H_{m}\right)$, compared to those of crystallized samples from approach II. Additionally, the authors observed that samples obtained from approach III exhibited a longer sequence of ET and L, which therefore resulted in a lowering of solubility of the materials in chloroform, but an increase in their crystallisability and $T_{m}$.

In this study, a similar synthesis procedure to that of approach I was employed, and copolymers obtained from batches no.3-4 show nearly identical $\mathrm{X}_{(\mathrm{ET})}$ and $\mathrm{Y}_{(\mathrm{L})}$ values to those reported by Grzebieniak [17]. Similar $T_{m}$ and solubility in chloroform are also observed in these samples. Our copolymers synthesized from the novel synthesis procedure, however, showed an intriguing solubility property. The materials from batches no.5-8, synthesized in the presence of thermo-stabilizers, are now hardly dissolved in chloroform (see Table 2), despite having comparable lengths of ET and L to the copolymers from approach I [17]. This reflects that the differences in the copolymer solubility cannot be simply explained by the difference in $\mathrm{X}_{(\mathrm{ET})}$ and $\mathrm{Y}_{(\mathrm{L})}$ values, but other factors may also play an important role in controlling the physicochemical properties of these copolymers. By carefully examining further results on $T / L$ ratio, $B, L_{n, E T}$, and $L_{n, L}$, it is also unlikely to consistently correlate these individual parameters to the copolymer solubility. This noncorrelation is also observed when different catalysts were employed in batches no.9-11 (as summarized in Table 3).

The $T_{g}$ of samples from batches no.4-8 is observed at the temperature ranging from 42 to $53^{\circ} \mathrm{C}$. This is significantly lower than the $62-67^{\circ} \mathrm{C}$ values reported by Grzebieniak [17], which is not surprising as the copolymers obtained here have lower molecular weight. Nonetheless, $T_{m}$ of these samples is in the same range and depends strongly on the average length of ET $\left(\mathrm{X}_{(\mathrm{ET})}\right.$ and $\left.\mathrm{L}_{\mathrm{n}, \mathrm{ET}}\right)$. These findings demonstrate that crystallization of the copolymers is possible when a suitable length of ET sequence is met. Moreover, the molecular weight imposes much smaller influence on the $T_{m}$ than the chemical structure when the molecular weight is beyond a certain value. Interestingly, $\Delta H_{m}$ of copolymers from batches no.5-8 is remarkably higher than that of batch no.1-4 and that of approach I's samples [17]. It is speculated that this higher amount of crystalline phase is because the thermo-stabilizers act as a nucleating agent in the nucleation step of crystallization. Differences in crystalline content of these two groups of materials, therefore, results in the difference in their solubility.

As mentioned previously, solubility of the copolyester cannot be easily predicted from the parame- 
ters collected from NMR spectra. It should be noted that this property is, however, correlated to or in good agreement with $\Delta H_{m}$ of the copolymers. A good solubility in chloroform is only observed in copolymers incapable of crystallization. This implies that information on $\mathrm{X}_{(\mathrm{ET})}$ and $\mathrm{L}_{\mathrm{n}, \mathrm{ET}}$ values is insufficient to provide in-depth information on crystallization behavior of the copolymers, but is satisfactory to use for interpreting or predicting their $T_{m}$.

\subsection{Thermal stability of as-synthesized copolyesters}

The effects of synthesis conditions, thermo-stabilizers, and catalysts on the thermal stability of the copolymers were investigated by employing TGA experiments. The thermograms of corresponding copolymers reported in Tables 1-3 are demonstrated in Figures 4-6, respectively. The thermograms are presented in comparison with those of commercial PET (acquired from the Nestle ${ }^{\circledR}$ drinking water bottle) and Cargil Dows' PLLA ( $M_{n} \sim$ $100 \mathrm{~K})$. From the insets of Figures 4-6, it is clearly shown that most of the copolymers synthesized in this work have lower on-set decomposition temperature than that of the commercial polymers. This is probably due to thermal degradation of the low molecular weight fraction of the copolymers. Intriguingly, more than $90 \%$ composition of the synthesized copolyesters has greater thermal stability than the high MW aliphatic PLLA. At a temperature near $415^{\circ} \mathrm{C}$, PLLA is completely decomposed, while the relative mass of the copolyesters from batches no.2-11 and the commercial PET remains at about $65 \%$. This implies that at least $65 \%$ composition of the copolyesters exhibits thermal stability comparable to PET.

Figures 5-6 show TGA thermographs of samples from batches no.4-11. Details on the initial stage of thermal degradation, as shown in the insets, indicate that only the samples from batches no. 8 and 11 have better thermal stability than material from batch no.4. This is in good accord with $M_{n}$ results obtained from NMR spectra. It is therefore concluded that $M_{n}$ results are better representations for relative molecular weight of copolymers than the reduced viscosity. This also proves that the method used to calculate $M_{n}$ reported by Olewnik et al. [19] is suitable for application in this copolymer system.

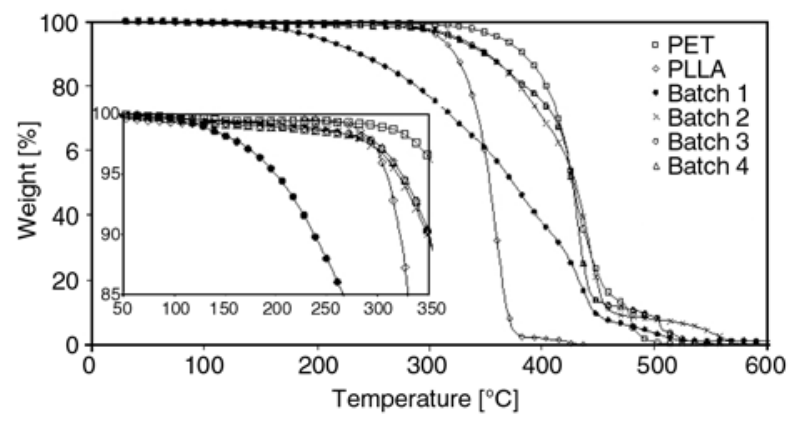

Figure 4. TGA thermograms of copolymers batches no. $1-4$, PET, and PLLA

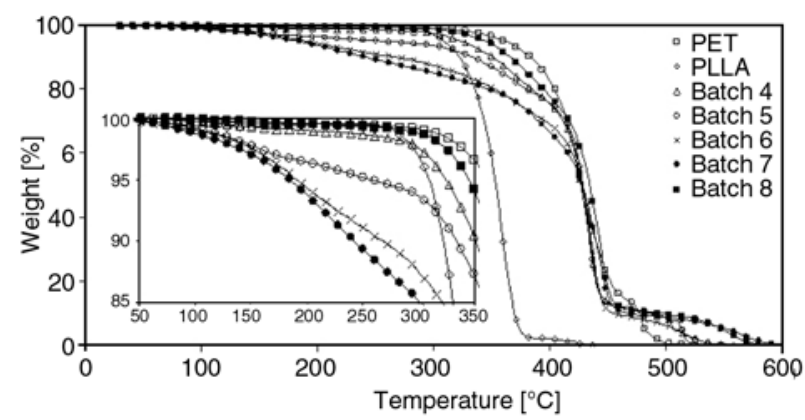

Figure 5. TGA thermograms of copolymers batches no.4-8, PET, and PLLA

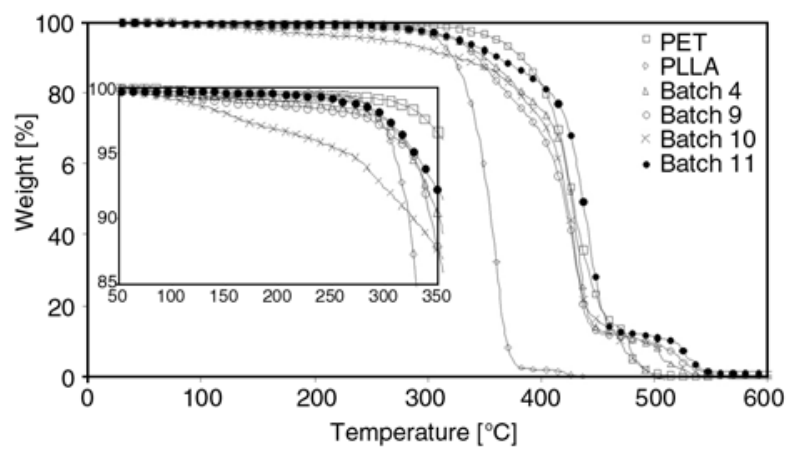

Figure 6. TGA thermograms of copolymers batches no.4, 9-11, PET, and PLLA

\section{Conclusions}

Lactic acid/ethylene terephthalate copolymers are synthesized by polycondensation of lactic acid, DMT, and EG. Effects of reaction conditions on the molecular weight of the copolymers, or the extent of polymerization were first investigated. In the synthesis reactions using Tin(II) octoate as a catalyst, low molecular weight copolymer was obtained when the reaction was carried out at $180^{\circ} \mathrm{C}$. The molecular weight of copolymers can be enhanced by increasing reaction temperatures and employing excess amounts of EG to DMT. However, degradation was observed at $220^{\circ} \mathrm{C}$. This can be avoided when TPP is applied as a thermo-stabilizer at an early stage of polymerization. The results on effects 
of catalysts on the efficiency of the reaction indicated that among 4 types of catalysts employed in this study, $\mathrm{Sb}_{2} \mathrm{O}_{3}$ and Tin(II) octoate are potentially suitable for this reaction, as these yield copolymers with the highest molecular weight.

Reaction conditions also have remarkable effect on chain structure and properties of the copolyesters. This is evidenced by T/L ratio, degree of randomness, and the average length of ET and L sequence $\left(\mathrm{X}_{(\mathrm{ET})}, \mathrm{L}_{\mathrm{n}, \mathrm{ET}}, \mathrm{Y}_{(\mathrm{L})}\right.$ and $\left.\mathrm{L}_{\mathrm{n}, \mathrm{L}}\right)$ results. All resulting copolymers show $\mathrm{T} / \mathrm{L}$ ratio values of higher than 1 , regardless of the initial equimolar of DMT/lactic acid. Additionally, random-structure characteristic (B 1) was observed in copolymers with moderate molecular weight $\left(\sim 2000 M_{n}\right)$.

Differences in physical properties of the resulting copolyesters are revealed by solubility results, $T_{g}$, $T_{m}, \Delta H_{m}$, and TGA thermograms. It is found that the average length of ET sequence imposes considerable influence on $T_{m}$ of the copolymers. The $T_{g}$ value of the copolymers is, however, not only in relation with the average ET length, but also the molecular weight of the copolymers. This is probably due to the moderate molecular mass of the samples. Although the dissimilarity of the copolyesters solubility is significantly not correlated to any chemical-structure related parameters, the results at hand show good connection with the sample crystalline content. Essentially, copolymers with high $\Delta H_{m}$ are unlikely to dissolve in chloroform. In addition, TGA thermograms reveal that thermal stability of the copolymers is greater than that of high molecular weight PLA, reflecting the enhancement of this property when aromatic constituents are incorporated into the structure.

\section{Acknowledgements}

Financial supports of this work are provided by A New Researcher Scholarship of CSTS-NSTDA-MOST, Thailand (grant no. F-31-102-09-01), and partly by Research Grants for Development of New Faculty Staffs, Chulalongkorn University, Thailand.

\section{References}

[1] Gerald S., Scott G.: Degradable polymers: Principles and applications. Kluwer Academic Publishers, London (2002).
[2] Albertsson A-C., Barnstedt C., Karlsson S.: Degradation of enhanced environmentally degradable polyethylene in biological aqueous media: Mechanisms during the first stages. Journal of Applied Polymer Science, 51, 1097-1105 (1994). DOI: 10.1002/app.1994.070510616

[3] Ki H. C., Park O. O.: Synthesis, characterization and biodegradability of the biodegradable aliphatic-aromatic random copolyesters. Polymer, 42, 1849-1861 (2001). DOI: $\underline{10.1016 / \mathrm{S} 0032-3861(00) 00466-3}$

[4] Gilding D. K., Reed A. M.: Biodegradation polymers for use in surgery - poly(ethylene oxide) poly(ethylene terephthalate) (PEO/PET) copolymers: 1. Polymer, 20, 1454--1458 (1979). DOI: 10.1016/0032-3861(79)90008-9

[5] Reed A. M., Gilding D. K.: Biodegradable polymers for use in surgery - poly(ethylene oxide) poly(ethylene terephthalate) (PEO/PET) copolymers: 2. Polymer, 22, 499-504 (1981). DOI: $10.1016 / 0032-3861(81) 90169-5$

[6] Kitotsukuri T., Masuda T., Tsutsumi N., Sakai W., Nagata M.: Poly(ethylene terephthalate copolymer)s with smaller amounts of poly(ethylene glycol)s and poly(butylene glycol)s. Polymer, 36, 2629-2635 (1995). DOI: $10.1016 / 0032-3861(95) 91211-0$

[7] Heidary S., Gordon B.: Hydrodegradable polyethylene terephthalate. Polymeric Materials Science and Engineering, 67, 190-191 (1992).

[8] Heidary S., Gordon B.: Hydrolyzable poly(ethylene terephthalate). Journal of Environmental Polymer Degradation, 2, 19-26 (1994). DOI: $\underline{10.1007 / \mathrm{BF} 02073483}$

[9] Nagata M., Kitotsukuri T., Minami S., Tsutsumi N., Sakai W.: Enzymatic degradation of poly(ethylene terephthalate) copolymers with aliphatic dicarboxylic acids and/or poly(ethylene glycol). European Polymer Journal, 33, 1701-1705 (1997). DOI: $10.1016 /$ S0014-3057(97)00063-3

[10] Witt U., Müller R-J., Deckwer W-D.: Biodegradation behavior and material properties of aliphatic/aromatic polyesters of commercial importance. Journal of Environmental Polymer Degradation, 5, 81-89 (1997).

[11] Witt U., Müller R-J., Augusta J., Widdecke H., Deckwer W-D.: Synthesis and biodegadability of polyesters based on 1,3-propanediol. Macromolecular Chemistry and Physics, 195, 793-802 (1994). DOI: 10.1002/macp.1994.021950235

[12] Witt U., Müller R-J., Deckwer W-D.: Biodegradation of polyester copolymers containing aromatic compounds. Journal of Macromolecular Science Part A: Pure and Applied Chemistry, 32, 851-856 (1995). DOI: $10.1080 / 10601329508010296$

[13] Witt U., Müller R-J., Deckwer W-D.: New biodegradable polyester-copolymers from commodity chemicals with favorable use properties. Journal of Environmental Polymer Degradation, 3, 215-223 (1995). DOI: $\underline{10.1007 / \mathrm{BF} 02068676}$ 
[14] Marten E., Müller R-J., Deckwer W-D.: Studies on the enzymatic hydrolysis of polyesters: II. Aliphatic - aromatic copolyesters. Polymer Degradation and Stability, 88, 371-381 (2005).

DOI: $10.1016 /$ j.polymdegradstab.2004.12.001

[15] Valiente N., Lalot T., Brigodiot M., Maréchal E.: Enzymatic hydrolysis of phthalic unit containing copolyesters as a potential tool for block length determination. Polymer Degradation and Stability, 61, 409-415 (1998).

DOI: $\underline{\text { 10.1016/S0141-3910(97)00226-7 }}$

[16] Witt U., Einig T., Yamamoto M., Kleeberg I., Deckwer W-D., Müller R-J.: Biodegradation of aliphaticaromatic copolyesters: Evaluation of the final biodegradability and ecotoxicological impact of degradation intermediates. Chemosphere, 44, 289-299 (2001). DOI: $10.1016 / \mathrm{S} 0045-6535(00) 00162-4$

[17] Grzebieniak K.: Copolyesters of ethylene terephthalate and lactic acid susceptible to hydrolytic degradation. Fibres and Textiles in Eastern Europe, 4, 34-37 (1996).
[18] Grzebieniak K., Ratajska M., Strobin G.: Estimation of hydrolysis and biodegradation processes in ethylene terephthalate and lactic acid copolymers. Fibres and Textiles in Eastern Europe, 9, 61-65 (2001).

[19] Olewnik E., Czerwiński W., Nowaczyk J., Sepulchre M. O., Tessier M., Salhi S., Fradet A.: Synthesis and structural study of copolymers of L-lactic acid and bis(2-hydroxyethyl terephthalate). European Polymer Journal, 43, 1009-1019 (2007).

DOI: $10.1016 / j . e u r p o l y m j .2006 .11 .025$

[20] Olewnik E., Czerwiński W., Nowaczyk J.: Hydrolytic degradation of copolymers based on L-lactic acid and bis-2-hydroxyethyl terephthalate. Polymer Degradation and Stability, 92, 24-31 (2007).

DOI: $10.1016 /$ j.polymdegradstab.2006.10.003

[21] Tessier M., Fradet A.: Determination of the degree of randomness in condensation copolymers containing both symmetrical and unsymmetrical monomer units: A theoretical study. e-Polymers, no. 30 (2003).

[22] Kenwright A. M., Peace S. K., Richards R. W., Bunn A., MacDonald W. A.: End group modification in poly(ethylene terephthalate). Polymer, 40, 2035-2040 (1999).

DOI: $\underline{10.1016 / \mathrm{S} 0032-3861(98) 00433-9}$ 